\title{
Expanding Access to Biodiversity Literature
}

\author{
Mariah Lewis $\ddagger$ \\ ‡ New York Botanical Garden, New York, United States of America
}

Corresponding author: Mariah Lewis (mlewis@nybg.org)

Received: 09 Aug 2017| Published: 10 Aug 2017

Citation: Lewis M (2017) Expanding Access to Biodiversity Literature. Proceedings of TDWG 1: e20146. https://doi.org/10.3897/tdwgproceedings.1.20146

\begin{abstract}
Through an Institute of Museum and Library Services (IMLS)-funded grant called Expanding Access to Biodiversity Literature (EABL), the Biodiversity Heritage Library (BHL) has adapted its digitization and metadata workflows to accommodate small organizations outside the consortium that would like to contribute unique content to $\mathrm{BHL}$ but lack the resources to do so. This presents several challenges: ingesting born digital and alreadydigitized material; training partners on BHL's metadata creation tool, Macaw; the need for expanded copyright metadata and display fields in the user interface; and defining articles and other bibliographic "segments." This presentation will discuss the efforts of EABL to address these challenges and provide data for evaluating progress toward the grant's stated goals.
\end{abstract}

\section{Keywords}

biodiversity; libraries; expanding access

\section{Presenting author}

Mariah Lewis 


\section{Grant title}

Expanding Access to Biodiversity Literature

\section{Hosting institution}

Biodiversity Heritage Library 